\title{
Dictiocaulosis en vacas de cría en la provincia de Buenos Aires, Argentina: descripción de dos brotes
}

\author{
Dictyocaulosis in beef cows in Buenos Aires province, Argentina: \\ description of two outbreaks
}

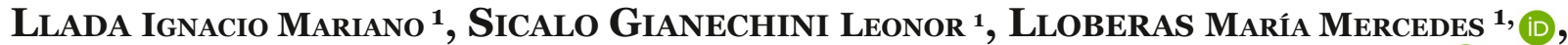 Morrell Eleonora lidia ${ }^{\mathbb{D}}$, Odriozola Ernesto Raúl ${ }^{1}$, Cantón Germán José ${ }^{\mathbb{D}, * *}$}

1. Grupo de Sanidad Animal, Instituto Nacional de Tecnología Agropecuaria (INTA), Balcarce, Argentina.

\footnotetext{
* Correo electrónico del autor de contacto: canton.german@inta.gob.ar
}

\begin{abstract}
Resumen
La dictiocaulosis o bronquitis verminosa es ocasionada por Dictyocaulus viviparus, un nematode de ciclo de vida directo, y está asociada, mayormente, a brotes de enfermedad clínica en bovinos jóvenes en su primera temporada de pastoreo. El presente trabajo describe dos brotes de bronquitis verminosa que provocó la mortandad de entre el 13,6 \% y el 15,7 \% de dos rodeos de vacas de cría de establecimientos de la provincia de Buenos Aires, Argentina. En ambos brotes, los hallazgos clínico-patológicos en los animales afectados y la presencia de nematodes pulmonares, en algunos casos solo observados en el estudio histopatológico, permitieron confirmar este diagnóstico.
\end{abstract}

\section{Palabras clave}

Dictyocaulus, bronquitis verminosa, bovinos

\begin{abstract}
Dictyocaulosis or parasitic bronchitis is caused by Dictyocaulus viviparus, a direct life cycle nematode, and is most frequently associated with clinical disease in young cattle during their first grazing season. This work describes two outbreaks of dictyocaulosis, in two cow-calf farms in Buenos Aires province, Argentina that caused the death of $13.6 \%$ and $15.7 \%$ of animals, respectively. In both outbreaks, clinical and pathological findings, and the presence of nematodes in respiratory tract, in some cases only observed in the histopathological analysis, allowed diagnosis confirmation.
\end{abstract}

\section{Key words}

Lungworm, parasitic bronchitis, bovine

Fecha de recepción: 29/01/2020

Fecha de revisión: 06/04/2020

Fecha de aprobación: 12/05/2020
ANALECTA VeT 2020; Enero-Junio; 40(1):25-32

Impresa ISSN 03655 14-8 Electrónica ISSN 1514-2590

doi.org/10.24215/15142590eo47 


\section{Introducción}

Dictyocaulus viviparus es el único nematodo trichostrongilideo (Strongylida: Dictyocaulidae), que parasita los bronquios y bronquiolos del pulmón bovino (Panuska, 2006). Las hembras adultas de $D$. viviparus ponen huevos larvados que eclosionan en las vías respiratorias y estos son transportados hacia la cavidad bucal mediante esputos para luego ser deglutidos y eliminados en la materia fecal como larva $1(\mathrm{~L} 1)$. El ciclo de vida en el hospedador consta de 4 fases: de penetración sin signos clínicos evidentes, prepatente con manifestaciones clínicas, patente con presencia de adultos en vías respiratorias y L1 en heces y, por último, una fase pospatente con escasa presencia de adultos en bronquios y larvas en materia fecal (Andrews \& Kennedy, 1997; Panuska, 2006).

El desarrollo de las larvas en la pastura es óptimo en condiciones ambientales con alta humedad, bajas temperaturas (entre 5 y $27^{\circ} \mathrm{C}$ ) y baja radiación solar. Las L1 y L2 son especialmente susceptibles a bajas temperaturas, a diferencia de las L3 infectivas que muestran mayor sobrevida a temperaturas de entre 3 y $6{ }^{\circ} \mathrm{C}$. Asimismo, se menciona que las L3 pueden sobrevivir entre 6 y 12 meses en la pastura cuando se dan condiciones favorables, aunque difícilmente sobrevivan al verano (Eysker \& van Miltenburg, 1988; Michael 1969). Sin embargo, los brotes de bronquitis verminosa suelen observarse hacia fin del invierno o a principios de la primavera, cuando los niveles de infestación de las pasturas han aumentado, debido a pastoreos intensivos (de 3 a 5 meses) en el mismo potrero, asociado o no a la presencia de animales portadores (Eysker \& van Miltenburg, 1988).

Cuando la infestación de la pastura es alta, es factible que la enfermedad se desarrolle en 3 a 4 semanas luego del ingreso al potrero; mientras que, cuando es baja, los primeros signos clínicos suelen observarse entre las 8 y las 10 semanas con la segunda o tercera generación de parásitos (Saatkamp et al., 1994). Una vez que se establecen ciertos niveles de inmunidad en el rodeo, es poco probable que se desarrolle la enfermedad (Michel, 1969).

Los signos clínicos varían según el estado inmunitario del animal, los niveles de infestación de las pasturas y la fase de la enfermedad (Eysker \&van Miltenburg, 1988). Durante la fase prepatente, las larvas en maduración en bronquios y bronquiolos, desencadenan una respuesta inflamatoria con predominio de eosinófilos, y en menor medida, neutrófilos, linfocitos y macrófagos. Como consecuencia, el exudado inflamatorio bloquea los pequeños bronquios y los bronquiolos generando un colapso de los alvéolos (Andrews \& Kennedy, 1997). Ya en la fase patente, el sistema inmune dirige su respuesta frente a los parásitos adultos y los huevos embrionados o larvas recientemente eclosionadas. Se produce una agrupación de macrófagos alveolares, que forman células gigantes multinucleadas con el objetivo de eliminar los parásitos (Schnieder et al., 1991). Las lesiones histológicas consisten en una bronquitis y bronquiolitis exudativa eosinofílica con traqueítis e intensa producción de exudado inflamatorio y moco que bloquean las vías aéreas (Andrews \& Kennedy, 1997). El epitelio plano alveolar normal (neumocitos tipo I) se ve afectado, y es reemplazado por células cuboideas (neumocitos tipo II), que dificultan la transferencia de gases entre la sangre y la luz alveolar (Schnieder et al., 1991). Las manifestaciones clínicas en esta etapa se corresponden con tos crónica, pérdida de peso, aumento en la frecuencia respiratoria, disnea severa y muerte (Andrews \& Kennedy, 1997).

Las lesiones ocasionadas por el parásito pueden complicarse debido a la presencia de bacterias oportunistas, agravando aún más el cuadro. Macroscópicamente, se observan áreas de atelectasia y consolidación en primera instancia en lóbulos caudales, de coloración rojiza a gris, con presencia de enfisema, que, de ser muy severo, puede llevar a confundir el cuadro con una neumonía intersticial aguda (Panciera \& Confer, 2010).

Por otro lado, en bovinos adultos, parcialmente inmunes, es posible que se produzca un síndrome de reinfección, en el que el sistema inmune reacciona severamente frente al contacto con altas cargas parasitarias. Una gran proporción del rodeo manifestará tos, disnea y depresión dos semanas luego de inicinada la infección, pudiendo conducir a la muerte de los animales afectados (Breeze, 1985).

Si bien es poco frecuente la aparición de signos clínicos en bovinos adultos, el objetivo de este trabajo es describir dos brotes de bronquitis verminosa que afectaron a rodeos de vacas de cría en la provincia de Buenos Aires, diagnosticados por el Servicio de Diagnóstico Veterinario Especializado del INTA Balcarce.

\section{Presentación de los casos}

\section{Brote 1:}

El primer brote ocurrió entre agosto $\mathrm{y}$ septiembre del año 2008 en un rodeo de 362 vacas de cría en un establecimiento agrícola-ganadero del partido de Ayacucho, provincia de Buenos Aires, las cuales ingresaron en el mes de junio provenientes de la provincia de Córdoba y presentaban una condición corporal regular. Lamentablemente, no pudo cotejarse la carga animal instantánea que tuvieron en esos potreros durante ese tiempo. A su arribo se les asignó un potrero de raigrás promocionado hacía dos años que presentaba baja disponibilidad forrajera. El mismo fue utilizado previamente con bovinos jóvenes de 
recría. Entre el 20 y el 25 de agosto se detectaron 3 vacas con signos respiratorios (salida de espuma por boca, decaimiento, tos, posición ortopnéica) y muerte. Se realizó la eutanasia y posterior necropsia (N1) a una vaca afectada de 6 años de edad, multípara, Aberdeen Angus. En la necropsia se observó enfisema pulmonar severo generalizado. Se tomaron muestras de tejidos que fueron fijados en formol y procesados en forma rutinaria para su posterior estudio histopatológico. El principal hallazgo fue una neumonía intersticial mixta moderada con edema intraalveolar severo y enfisema multifocal leve (figura 1). En la respuesta inflamatoria intersticial predominaban los neutrófilos y eosinófilos y, en menor proporción, los macrófagos y linfocitos (figura 2). Teniendo encuenta los hallazgos clínico-patológicos y la categoría afectada, se formuló un diagnóstico presuntivo de edema y enfisema pulmonar agudo (neumonía intersticial atípica ofog fever).

Los animales permanecieron en el mismo potrero, siendo, además, suplementados con grano de maíz y heno. Luego de las primeras muertes, y en el transcurso de un mes, se registraron otras 57 muertes $(15,7 \%$ de mortalidad), pese al tratamiento instaurado con antibióticos y antiinflamatorios (antiinflamatorios no esteroides a las hembras gestantes y esteroides a las no gestantes). La signología manifestada era similar a la observada inicialmente en los primeros animales afectados.

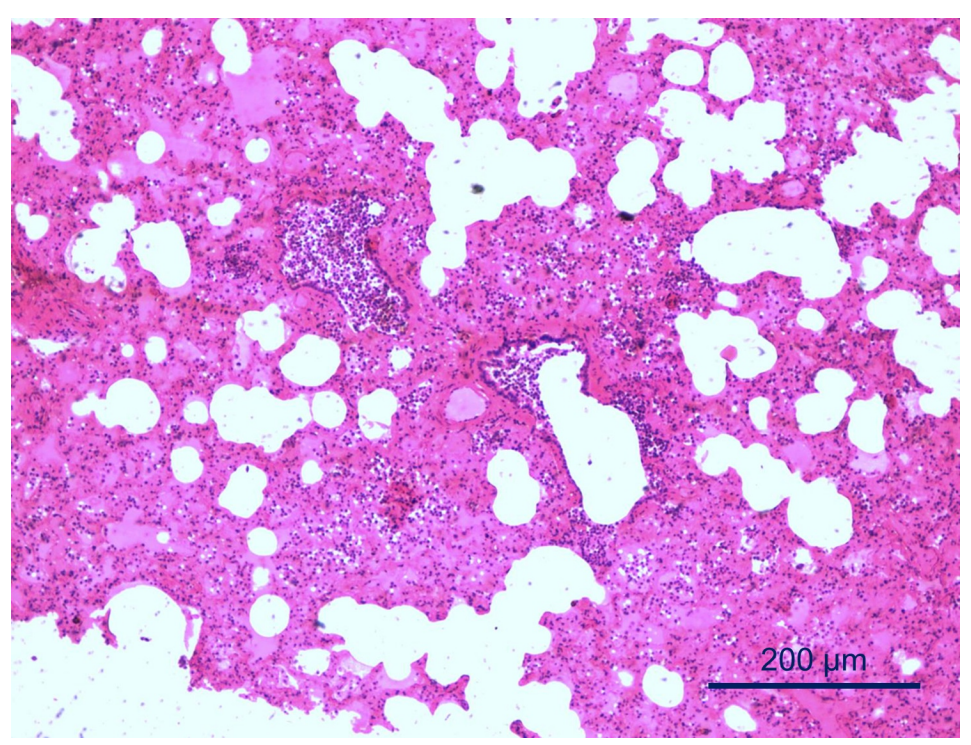

Figura 1. Necropsia N1. Neumonía intersticial mixta moderada con edema intraalveolar severo y enfisema multifocal leve. H-E. Barra = $200 \mu \mathrm{m}$

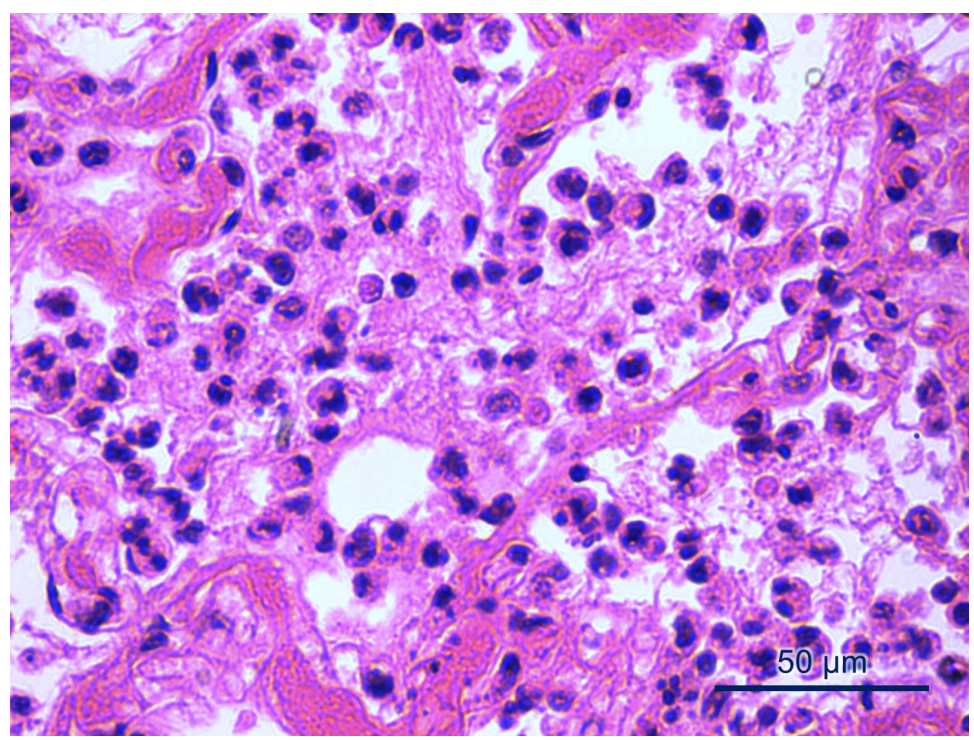

Figura 2. Bronconeumonía intersticial con predominio de neutrófilos y eosinófilos y en menor proporción macrófagos y linfocitos. H-E. Barra $=50 \mu \mathrm{m}$. 


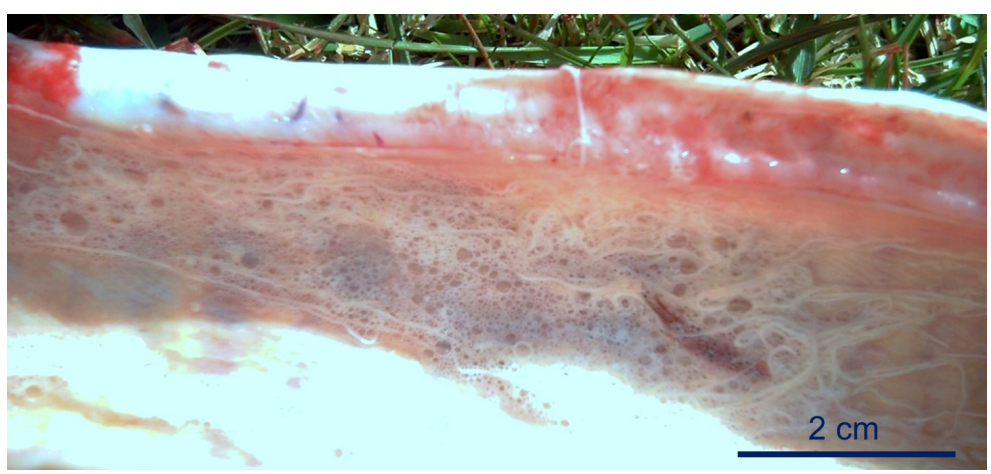

Figura 3. Necropsia N2. Abundantes nematodes blanquecinos, filiformes, morfológicamente compatibles con Dictyocaulus spp. en tráquea. Barra $=2 \mathrm{~cm}$.

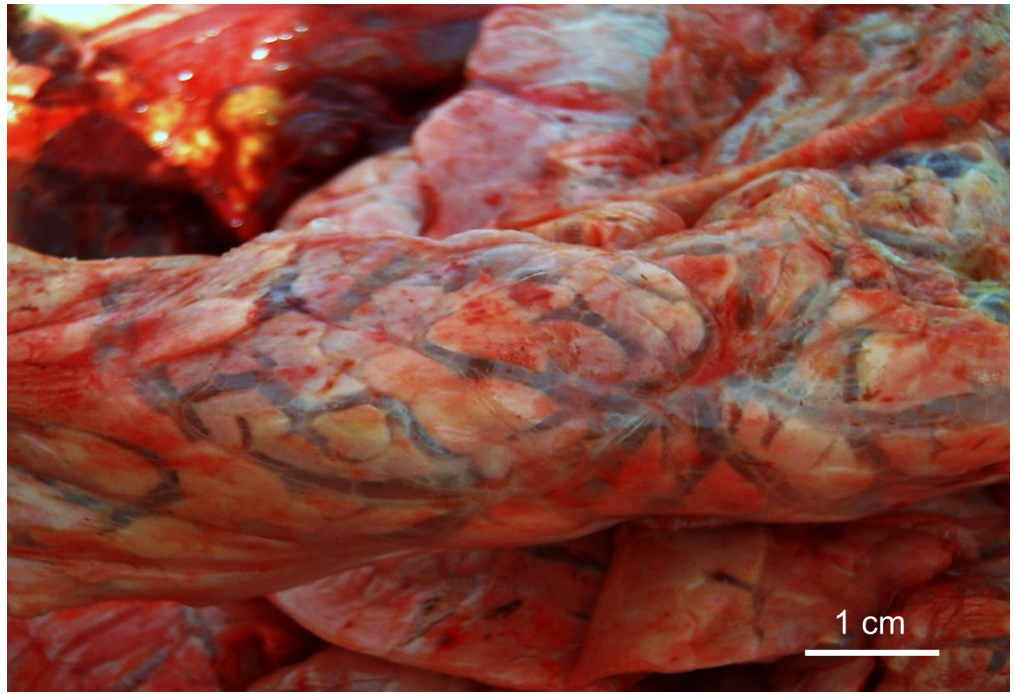

Figura 4. Necropsia N3. Enfisema pulmonar interlobulillar. Barra $=1 \mathrm{~cm}$.

El 17 de septiembre se realizó una nueva necropsia (N2) a una vaca Aberdeen Angus multípara que había muerto hacía aproximadamente 12 horas, por lo que presentaba un grado moderado de cambios post mortem. Se observó enfisema pulmonar generalizado severo y abundante presencia de nematodes blanquecinos, filiformes, de 8-10 cm de longitud, morfológicamente compatibles con Dictyocaulus spp. ocupando la luz traqueal (figura 3) y bronquios. Además, se observaron áreas multifocales de 3-4 cm de diámetro de atelectasia y edema pulmonar en el lóbulo cardíaco. Se observó ascitis (500 $\mathrm{ml}$ de líquido seroso ambarino) y edema en el mesenterio.

Ese mismo día se practicó eutanasia a otra vaca multípara Aberdeen Angus (N3) que presentaba disnea y posición ortopneica. Se observaron abundantes nematodes en bronquios, así como lesiones similares a las descriptas en la necropsia N2 (figura 4).

En el estudio histopatológico de las muestras de las vacas N2 y N3 se observó una bronconeumonía intersticial mixta severa con presencia de estructuras parasitarias (compatibles con nematodes juveniles) en la luz de alveolos y bronquiolos, con enfisema severo (figura 5). En los otros tejidos no se observaron lesiones relevantes. Los nematodes recolectados del parénquima pulmonar de las vacas N2 y N3 fueron luego identificados como Dictyocaulus spp. mediante su observación directa bajo lupa y sobre la base de sus características morfológicas.

Los hallazgos clínico-patológicos en los animales afectados y la presencia de nematodes pulmona-res, permitieron formular un diagnóstico defini-tivo de dictiocaulosis.

\section{Brote 2:}

El segundo brote ocurrió entre agosto y noviembre del año 2019 en un rodeo de 125 vacas y vaquillonas con cría al pie, en un establecimiento agrícola-ganadero del partido de Pehuajó, provincia de Buenos Aires. Desde el invierno habían 


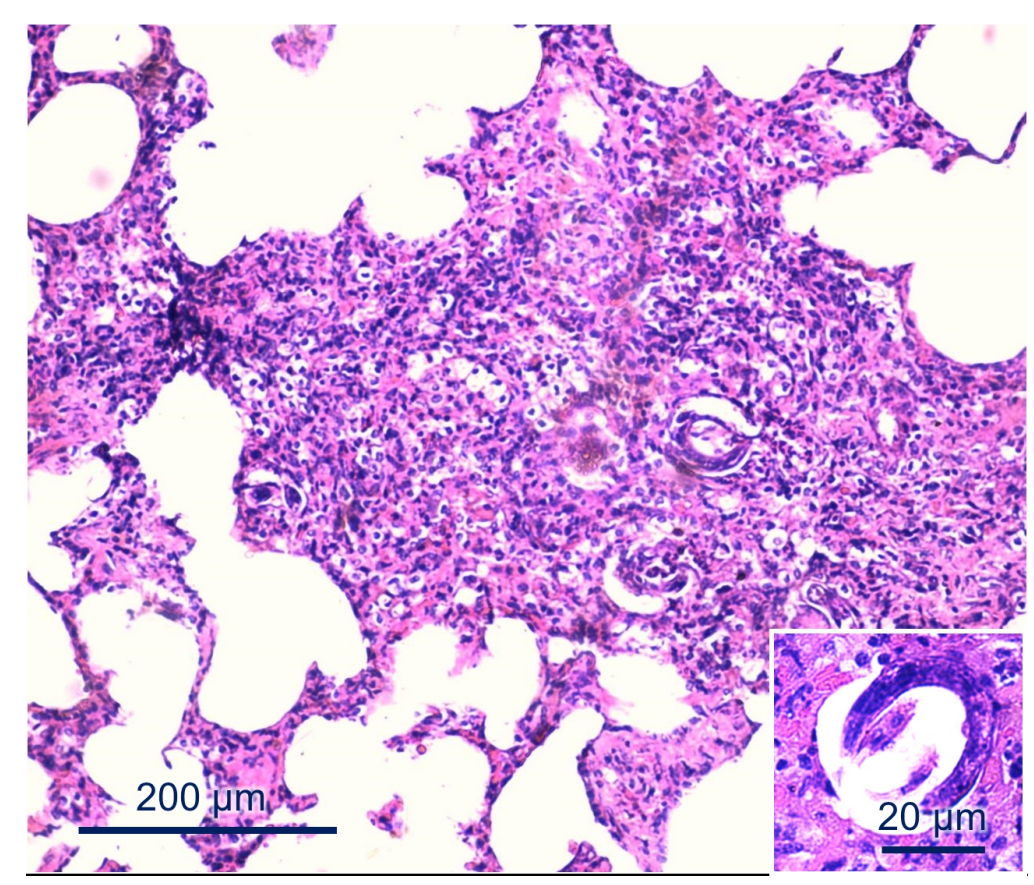

Figura 5. Necropsia N2. Bronconeumonía intersticial mixta severa con presencia de nematodes juveniles en la luz de alveolos y bronquiolos, con enfisema severo. H-E. Barra $=200 \mu \mathrm{m}$. En el recuadro se muestra, con mayor detalle, una larva de Dictyocaulus spp. H-E. Barra $=20 \mu \mathrm{m}$.

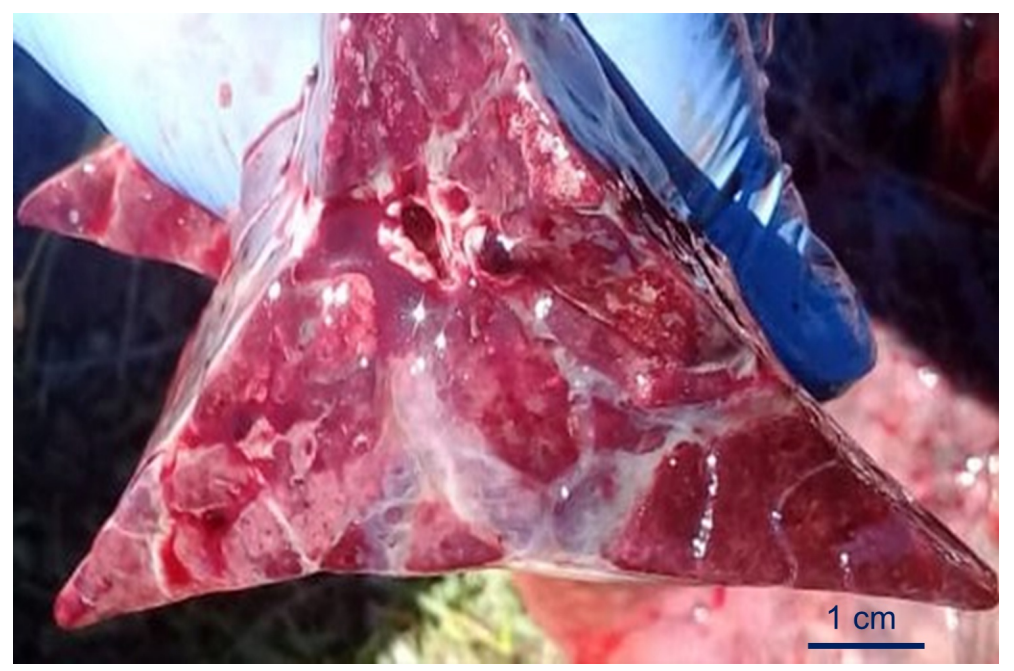

Figura 6. Necropsia N4. Edema pulmonar interlobulillar. Barra $=1 \mathrm{~cm}$.

estado pastoreando, con una elevada carga animal, diferentes potreros: inicialmente consumían campo natural, luego pasaron por un rastrojo de maíz, pasturas de agropiro, nuevamente campo natural y, por último, una pastura de un año de implantación, compuesta de festuca, cebadilla y trébol.

Desde agosto hasta fines de septiembre se había registrado la muerte de 5 vacas. Desde octubre habían muerto otros 12 animales (principalmente vacas y algunas vaquillonas) (13,6\% de mortalidad). Antes de la muerte, los animales se encontraban en decúbito con signos respiratorios, taquipnea $\mathrm{y}$, en algunos individuos, salida de espuma por ollares.

El 21 de noviembre se realizó la necropsia de 2 vacas. La primera (N4) era una vaquillona Aberdeen Angus (2 dientes), que presentaba una condición corporal regular, y había muerto hacía 8 horas. En la necropsia se observaron ambos pulmones congestivos y edema interlobulillar leve a moderado (figura 6). También había colecta de líquido color ámbar en cavidad torácica y petequias en la pleura parietal y pericardio.

Posteriormente se realizó la necropsia 


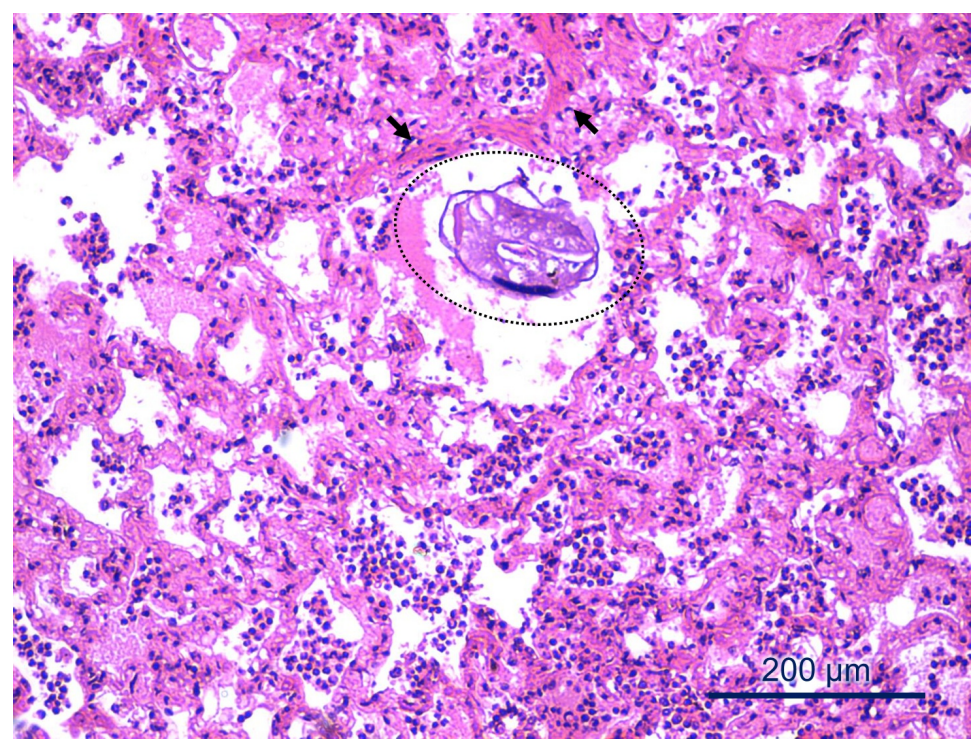

Figura 7. Necropsia N4. Neumonía intersticial mixta con hiperplasia del músculo liso de los septos alveolares (flechas), áreas de enfisema y presencia de larvas (ćrculo), compatibles con nematodes juveniles en el interior de alveolos y bronquiolos. H-E. Barra = $200 \mu \mathrm{m}$.

(N5) a una vaca multípara Aberdeen Angus ("cuarto de diente") que presentaba una condición corporal regular y había muerto hacía 8 horas, aproximadamente. Al abordar la cavidad torácica durante la necropsia, los pulmones no colapsaron, y se observó congestión y edema marcado. Se detectó una colecta de líquido color ámbar en cavidad torácica, petequias en epicardio, edema en el mesocolon, petequias en mucosa abomasal y contenido de materia fecal líquida de color verde oscuro en la luz de íleon, ciego y colon.

Microscópicamente se observó edema intraalveolar e interlobulillar difuso severo en ambos pulmones, con un infiltrado inflamatorio mixto (principalmente eosinófilos, neutrófilos y, en menor proporción, macrófagos y linfocitos) en la luz alveolar, bronquiolos y bronquios. También se observó hiperplasia del músculo liso de conductos alveolares o bronquiolos respiratorios, áreas de enfisema y presencia de nematodes juveniles en el interior de alveolos y bronquiolos (figura 7). En el intestino recolectado durante la segunda necropsia (N5) se observó un leve infiltrado mononuclear en la lámina propia, con dilatación de quilíferos centrales y presencia de algunos eosinófilos.

Durante la segunda necropsia (N5) se recolectó contenido cecal para intentar cultivo bacteriano, el que resultó negativo a la presencia de bacterias de importancia clínica.

Teniendo en cuenta los hallazgos clínicopatológicos en los animales afectados y la presencia de nematodes pulmonares, solo observados en el estudio histopatológico, se formuló un diagnóstico de dictiocaulosis.

\section{Discusión y conclusiones}

El presente trabajo describe dos brotes de bronquitis verminosa en bovinos adultos, dejando en evidencia las dificultades que surgen para arribar al diagnóstico de esta parasitosis, principalmente en estadios clínicos iniciales.

La bronquitis verminosa es una enfermedad raramente diagnosticada en vacas de cría. Por otro lado, las lesiones pulmonares microscópicas observadas en algunos animales (N1, N4 y N5), también pueden ocurrir en otras enfermedades respiratorias que suelen afectar a bovinos adultos, como, por ejemplo, el edema y enfisema pulmonar agudo. El síndrome de reinfección de la dictiocaulosis se produce por una respuesta inmune exacerbada, frente a un segundo contacto del animal con el parásito (Breeze, 1985). En los tejidos recolectados de la necropsia $\mathrm{N}_{1}$ no se observaron estructuras parasitarias, por lo que el diagnóstico presuntivo inicial de la enfermedad fue de edema y enfisema pulmonar agudo, aunque otras lesiones características de esta presentación no habían sido observados (proliferación de neumocitos tipo II en empalizada y presencia de membranas hialinas recubriendo los alvéolos edematosos y ductos alveolares) (Constable et al., 2017).

Los brotes de bronquitis verminosa no son comúnmente asociados a los sistemas de cría bovina donde el pastoreo es extensivo, con la consiguiente menor concentración de larvas disponibles en el pasto. En estos brotes, es posible que la baja disponibilidad forrajera y la elevada carga animal, hayan obligado a los animales al pastoreo cercano a las heces donde se encuentra la 
mayor cantidad de larvas infectivas disponibles. De todas formas, es factible que alguno de los potreros en los que estos animales estuvieron pastoreando, se hallara severamente infectado por el pastoreo previo de bovinos jóvenes. En el brote 1, las primeras muertes ocurrieron 60 días luego del ingreso de los animales, probablemente en las primeras generaciones de parásitos, independientemente de la presencia de animales carriers. Los animales pudieron ingresar infectados ya que no se cuenta con historial de los tratamientos antiparasitarios que habían recibido previamente. También se pudieron haber concentrado larvas en pasto en ese período, de modo que las reinfecciones fueron con mayor o alta carga. El tratamiento con corticoides aplicado luego de la primera visita, pudo haber también exacerbado el cuadro. En la N2 y N3 se observaron tanto adultos como larvas, lo que sugiere una acumulación y falta de control de las sucesivas reinfecciones. Esto contrasta con lo ocurrido en los animales en el segundo brote ( 44 y $\mathrm{N}_{5}$ ), en los que solo se observaron formas inmaduras o juveniles de nematodes en el estudio histopatológico. A pesar de esto, en los casos severos es posible observar enfisema, edema intraalveolar y respuesta inflamatoria intersticial como lesiones predominantes, lo que puede conducir a un diagnóstico erróneo de neumonía intersticial (Panciera \& Confer, 2010). Estas lesiones coinciden con las observadas en el animal N1.

Por otro lado, la presentación clínica de dictiocaulosis en bovinos adultos, estaría indicando un pobre desarrollo de inmunidad frente a $D$. viviparus. El pasaje y muda de las L3 a L4 en los linfonódulos mesentéricos confiere una inmunidad temprana en la vida del animal, lo que permite que, finalizando el primer pastoreo o durante la segunda temporada de pastoreo, el ternero logre controlar esta parasitosis exitosamente (Eysker \& van Miltenburg, 1988). Se describe que, el uso excesivo de tratamientos antiparasitarios tempranamente en la vida del animal, puede evitar el contacto del sistema inmune con el nematodo e impedir el desarrollo de una base sólida de mecanismos de defensa (Ploeger, 2002). Sin embargo, esta información no pudo ser corroborada en este rodeo y es poco probable que haya sucedido.

En el brote 1, posiblemente la respuesta del sistema inmune de las vacas afectadas se haya visto comprometida por la administración de antiinflamatorios, según lo recomendado inicialmente ante un diagnóstico presuntivo erróneo. Esto pudo haber determinado que se incrementara la cantidad de casos clínicos y, en consecuencia, las muertes.

En estos dos brotes no se pudo realizar un diagnóstico coproparasitológico, debido a la naturaleza de los casos. Se recomienda realizar el monitoreo de larvas en materia fecal antes en el mismo día de extraída la muestra, ya que gran parte de las larvas pueden perderse (Rode \& Jørgensen, 1989). Esto representó una limitante dadas las distancias entre los establecimientos y el laboratorio. En estos dos brotes, se pudo confirmar la enfermedad mediante los hallazgos clínico-patológicos.

Los reportes de casos de dictiocaulosis en bovinos adultos son poco frecuentes en nuestro país. El diagnóstico de la enfermedad puede resultar difícil, dependiendo principalmente del momento del ciclo parasitario en el cual se evalúa el rodeo afectado. Sin embargo, esta enfermedad seha registrado con mayor frecuencia en las últimas décadas, traduciéndose en importantes pérdidas económicas (David, 1997; Holzhauer et al., 2011; Van Dijk, 2004). Por lo tanto, la ocurrencia de esta presentación clínica emergente en animales adultos debería ser tenida en cuenta a la hora de establecer un calendario sanitario anual (Ploeger, 2002). Como en todas las enfermedades del complejo respiratorio, el reconocimiento temprano de la enfermedad, la recolección de muestras en distintos sectores del tejido pulmonar y el correcto tratamiento es fundamental para evitar el compromiso de la vida del animal y la salud del rodeo.

\section{Agradecimientos}

A Lilian Lischinsky, Bernardino Borda y Carlos Entrocasso por la colaboración técnica y científica para poder completar este trabajo. Además, agradecemos a Daniel Aguado y Lucas Massola, veterinarios de la actividad privada por la provisión de toda la información anamnésica que permitió explicar la ocurrencia de estos brotes.

\section{Conflicto de intereses}

No existe conflicto de intereses, incluyendo entre estos últimos las relaciones financieras, personales o de otro tipo con otras personas $\mathrm{u}$ organizaciones que pudieran influir de manera inapropiada en el trabajo.

\section{Bibliografía}

Andrews G, Kennedy G. 1997. Respiratory diagnostic pathology. Veterinary Clinics of North America: Food Animal Practice. 13:515-47. doi: 10.1016/So749-0720(15)30312-1

Breeze R. 1985. Parasitic bronchitis and pneumonia. Veterinary Clinics of North America: Food Animal Practice. 1:277-87.

doi: 10.1016/s0749-0720(15)31327-x 
Constable PD, Hichcliff KW, Done SH, Grunberg W. 2017. Respiratory system. En: Ibid (Eds.). Veterinary Medicine. 11th Edition. W.B.Saunders, Edinburgh, UK, pp. 965-9.

David G. 1997. Survey on lungworm in adult cattle. Veterinary Record. 141:343-4.

Eysker M, van Miltenburg L. 1988. Epidemiological patterns of gastrointestinal and lung helminth infections in grazing calves in The Netherlands. Veterinary Parasitology. 29:29-39. doi: 10.1016/0304-4017(88)90005-2

Holzhauer M, van Schaik G, Saatkamp H, Ploeger H. 2011. Lungworm outbreaks in adult dairy cows: estimating economic losses and lessons to be learned. Veterinary Record. 169:494.

doi: 10.1136/vr.d4736

Michel J. 1969. The epidemiology of some nematode infections in calves. Veterinary Record. 85:323-6. doi: 10.1136/vr.85.12.323

Panciera R, Confer A. 2010. Pathogenesis and pathology of bovine pneumonia. Veterinary Clinics of North America: Food Animal Practice. 26:191214. doi: 10.1016/j.cvfa.2010.04.001

Panuska C. 2006. Lungworms of ruminants. Veterinary Clinics of North America: Food Animal
Practice. 22:583-93.

doi: 10.1016/j.cvfa.2006.06.002

Ploeger H. 2002. Dictyocaulus viviparus: reemerging or never been away? Trends in Parasitology. 18:329-32.

doi: 10.1016/s1471-4922(02)02317-6

Rode R, Jørgensen J. 1989. Baermannization of Dictyocaulus spp. from faeces of cattle, sheep and donkeys. Veterinary Parasitology. 30: 205-11.

doi: 10.1016/0304-4017(89)90016-2

Saatkamp H, Eysker M, Verhoeff J. 1994. Study on the causes of outbreaks of lungworm disease on commercial dairy farms in the Netherlands. Veterinary Parasitology 53: 253-61.

doi: 10.1016/0304-4017(94)90188-0

Schnieder T, Kaup F, Drommer W. 1991. Morphological investigations on the pathology of Dictyocaulus viviparus infections in cattle. Parasitology Research. 77: 260-5.

doi: 10.1007/bfoo930869

Van Dijk J. 2004. The epidemiology and control of dictyocaulosis in cattle. Cattle Practice. 12: 133-45. 